\title{
Multidisciplinary Approach for Correction of Obstructive Sleep Apnea
}

\author{
${ }^{1}$ Aarti B Madhaswar, ${ }^{2}$ VK Ravindranath, ${ }^{3}$ Prateek N Daga
}

\begin{abstract}
Obstructive sleep apnea (OSA) is the most common type of sleep apnea and is caused by complete or partial obstructions of the upper airway. In this study we are presenting a case report of 11-year-old male patient with enlarged adenoids and tonsils, convex profile, receded chin, lower lip trap, class II skeletal and dental relationship with increased overjet. Surgical removal of enlarged adenoids was done before commencement of twinblock therapy. After this, two-step advancement with expansion in both arches utilizing twin blocks was planned. Four months into the treatment, patient reported with history of facial trauma with avulsed maxillary left central incisor. Twin block was then modified with pontic as replacement for maxillary left central incisor. Sagittal correction resulting in class I molar relationship was achieved in next 6 months. Fixed appliance therapy was followed. The design of the appliance and the results achieved after the postfunctional therapy are presented in this case report.
\end{abstract}

Keywords: Class II, Functional appliance, Obstructive sleep apnea, Skeletal maturation, Twin block.

How to cite this article: Madhaswar $A B$, Ravindranath VK, Daga PN. Multidisciplinary Approach for Correction of Obstructive Sleep Apnea. J Contemp Dent 2016;6(3):189-193.

Source of support: Nil

Conflict of interest: None

\section{INTRODUCTION}

Obstructive sleep apnea (OSA) consists of repetitive episodes of shallow or paused breathing during sleep, despite the effort to breathe, accompanied by snoring. Obstruction of the upper respiratory track often results in mouth breathing, which may culminate in a habit. This habit may lead to muscular and postural anomalies, which may in turn cause entoskeletal malocclusions. ${ }^{1}$ Upper respiratory obstruction is frequently caused by

\footnotetext{
${ }^{1,3}$ Postgraduate Student, ${ }^{2}$ Professor and Head

${ }^{1,3}$ Department of Orthodontics, Mahatma Gandhi Mission's Dental College and Hospital, Navi Mumbai, Maharashtra, India

${ }^{2}$ Department of Orthodontics and Dentofacial Orthopedics Mahatma Gandhi Mission's Dental College and Hospital, Navi Mumbai, Maharashtra, India

Corresponding Author: Aarti B Madhaswar, Postgraduate Student, Department of Orthodontics, Mahatma Gandhi Mission's Dental College and Hospital, Navi Mumbai, Maharashtra, India Phone: +912227437935, e-mail: madhaswaraarti@gmail.com
}

enlarged adenoids and palatine tonsils. The orthodontist during the diagnoses of dentofacial anomalies may be the first clinician to notice the mouth breathing habit. The treatment modalities of adenoid hypertrophy range from dietary control and environmental modifications to dentofacial orthopedics, change of breathing exercises, and surgical procedures.

Functional appliances utilize the force generated by muscles to bring about skeletal and dental changes. There is an extensive literature which documents their potential in correction of jaw anomalies. ${ }^{2}$ Ample evidences are suggestive of it being one of the most successful appliances for the treatment of skeletal class II malocclusions. Bite registration is one of the most important step in fabrication of twin block and is mostly taken with the incisors in edge-to-edge relation. Many authors have suggested that greater orthopedic effect can be achieved by advancing bite gradually. ${ }^{3,4}$

\section{CASE REPORT}

An 11-year-old male patient reported to the Department of Orthodontics and Dentofacial Orthopedics with the chief complaint of forwardly placed upper front teeth. On extraoral examination, the patient has a convex profile, incompetent lips with an interlabial gap of $4 \mathrm{~mm}$, short upper lip length $(10 \mathrm{~mm})$, voluminous and everted lower lip, acute nasolabial angle, and deep mentolabial sulcus. On intraoral examination, constricted maxillary and mandibular arches, bilateral class II molar relation, and end one canine relation bilaterally, over jet of $12 \mathrm{~mm}$, enlarged adenoid and tonsils were noted. The pretreatment extraoral and intraoral photographs (Figs $1 \mathrm{~A}$ to D and $2 \mathrm{~A}$ to $\mathrm{E}$ ) were recorded. The patient was further probed with regards to mouth breathing habit, which lead to revelation of history of sleeplessness, day-time fatigue, repeated cold and sore throat incidences, breathlessness, and halitosis. Based on these findings, Massler's water holding and Zwemer ${ }^{5}$ butterfly tests were performed, which yielded positive result for mouth breathing.

The case was diagnosed as an OSA with skeletal class II division 1 malocclusion with orthognathic maxilla and retrognathic mandible. Cephalometric analysis (Table 1) confirmed diagnosis of class II skeletal base having horizontal growth pattern and reduced upper pharyngeal space (Figs 3A to C). Evaluation of patient's 

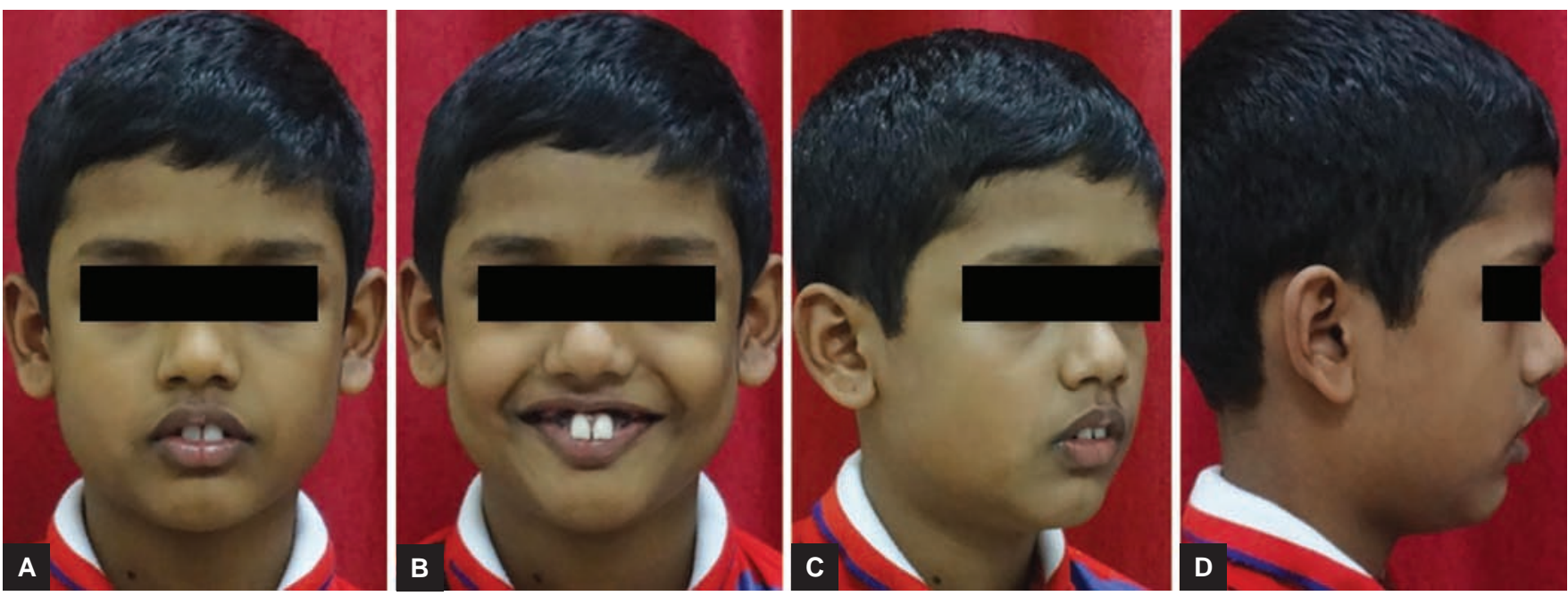

Figs $1 A$ to $D$ : Pretreatment extraoral photographs
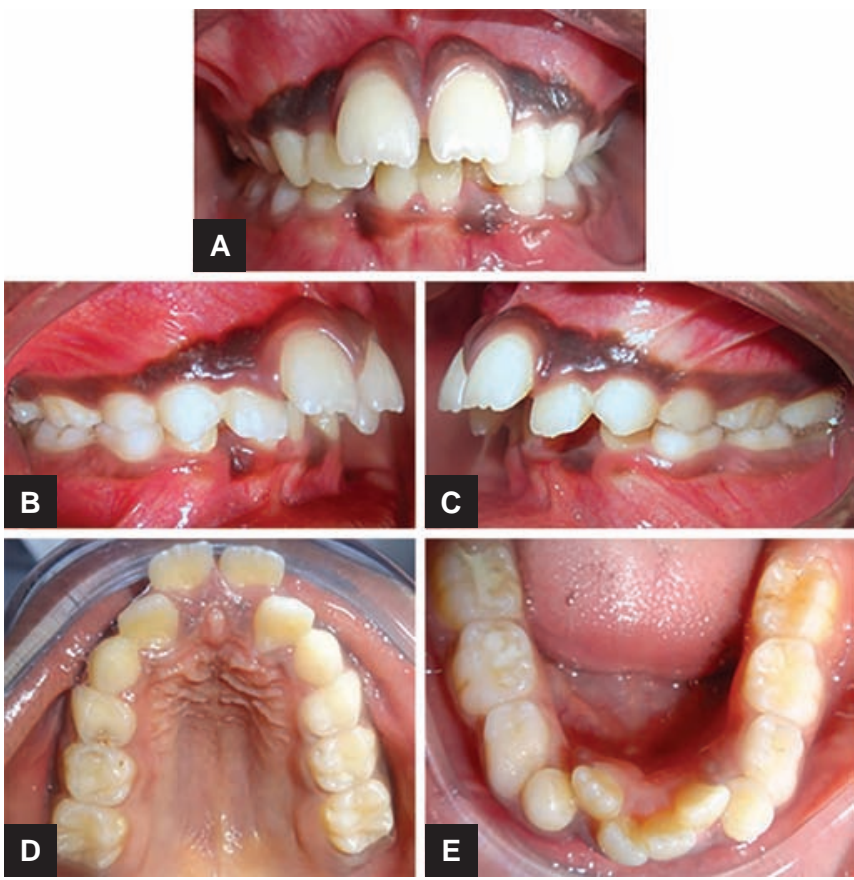

Figs $2 \mathrm{~A}$ to E: Pretreatment intraoral photographs
Table 1: Cephalometric analysis

\begin{tabular}{llll}
\hline Parameters & Pretreatment & $\begin{array}{l}\text { After adenoid } \\
\text { removal }\end{array}$ & $\begin{array}{l}\text { Post } \\
\text { functional }\end{array}$ \\
\hline SNA & $77^{\circ}$ & $77^{\circ}$ & $77^{\circ}$ \\
SNB & $70^{\circ}$ & $70^{\circ}$ & $75^{\circ}$ \\
ANB & $7^{\circ}$ & $7^{\circ}$ & $2^{\circ}$ \\
SN to GO-GN & $27^{\circ}$ & $28^{\circ}$ & $27^{\circ}$ \\
IMPA & $90^{\circ}$ & $90^{\circ}$ & $95^{\circ}$ \\
Wits appraisal & $+5 \mathrm{~mm}$ & $+5 \mathrm{~mm}$ & $+1 \mathrm{~mm}$ \\
Pharyngeal airway & & & \\
Upper & $3 \mathrm{~mm}$ & $15 \mathrm{~mm}$ & $16 \mathrm{~mm}$ \\
Lower & $8 \mathrm{~mm}$ & $10 \mathrm{~mm}$ & $10 \mathrm{~mm}$ \\
\hline
\end{tabular}

cervical radiograph indicated that he was at the peak of pubertal growth spurt with a considerable amount of growth remaining. In addition to this, patient showed positive visual treatment objective.

\section{Treatment Objective}

- Surgical removal of enlarged tonsils and adenoid for correction of OSA.
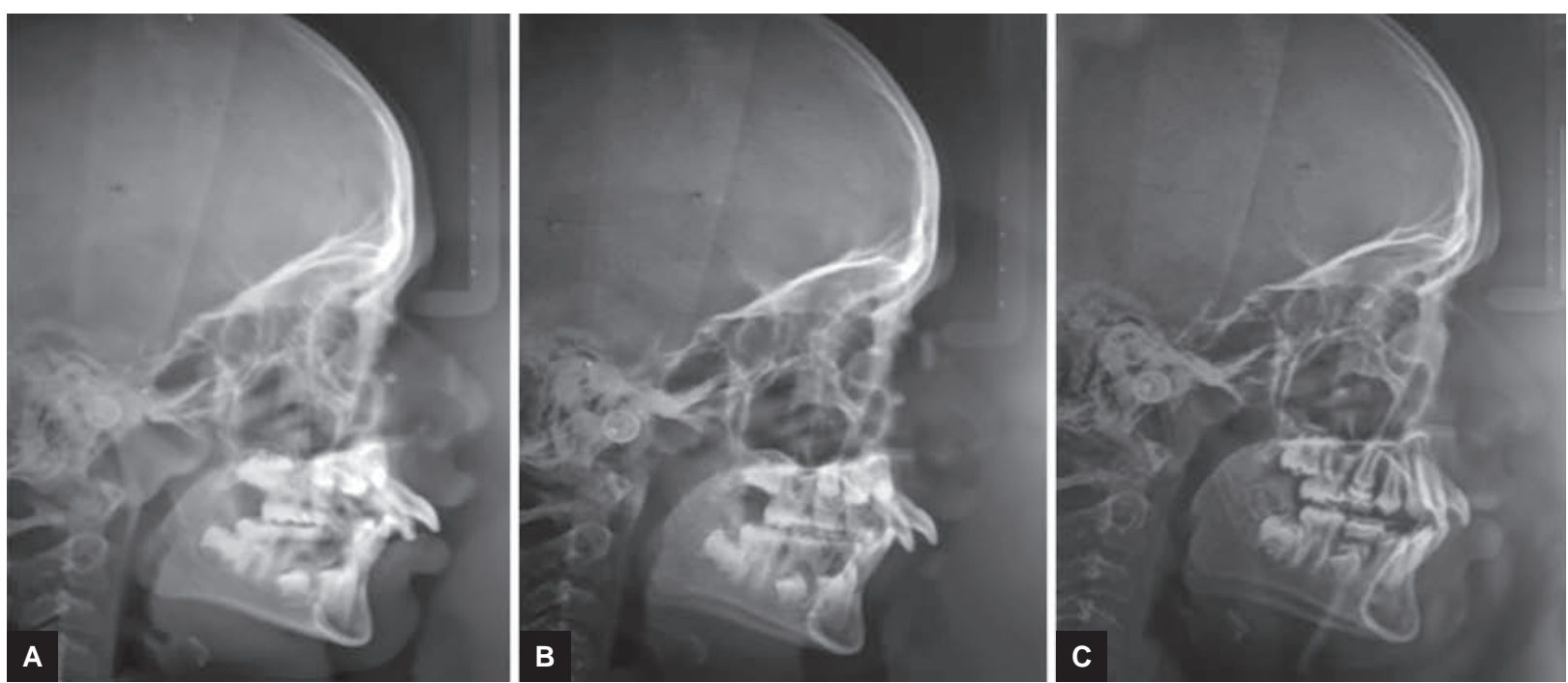

Figs 3A to C: (A) Pretreatment; (B) after adenoid removal; and (C) postfunctional 
- Skeletal correction of class II malocclusion using functional appliance (twin block by two-step advancement)

- Correction of Angle's class II malocclusion

- Achievement of normal over jet and overbite.

\section{Treatment Plan}

The treatment plan was surgical removal of enlarged tonsils and adenoid in conjunction with ENT surgeons. This was followed by two phases of orthopedic and orthodontic treatment. First phase involved correction of sagittal dysplasia using functional appliance therapy. The appliance utilized was twin blocks with expansion screws incorporated. The correction was carried out in two steps: First $6 \mathrm{~mm}$ advancement and a $5 \mathrm{~mm}$ advancement in the next step. Two-step advancement using twin block with expansion screws in both upper and lower arches was planned. The second phase of treatment consisted of fixed appliance therapy.

\section{Treatment Progress}

The case was studied and evaluated for enlarged tonsils and adenoid. The patient was referred to the Department of ENT, Mahatma Gandhi Mission's Dental College and Hospital, for their expert opinion. In conjunction with the ENT surgeons, decision was taken for surgical removal of adenoids. Patient underwent the surgery with an uneventful recovery. This was followed by the functional appliance phase. Construction bite was taken with $5 \mathrm{~mm}$ horizontal advancement and $4 \mathrm{~mm}$ vertical opening. Twin blocked was fabricated with expansion screw in both upper and lower arches. The twin block was delivered with the necessary patient instructions and follow-up was carried out regularly. Activation of expansion screw was done with two quarter turn a week for 4 weeks. Pterygoid response was noted at 3 months

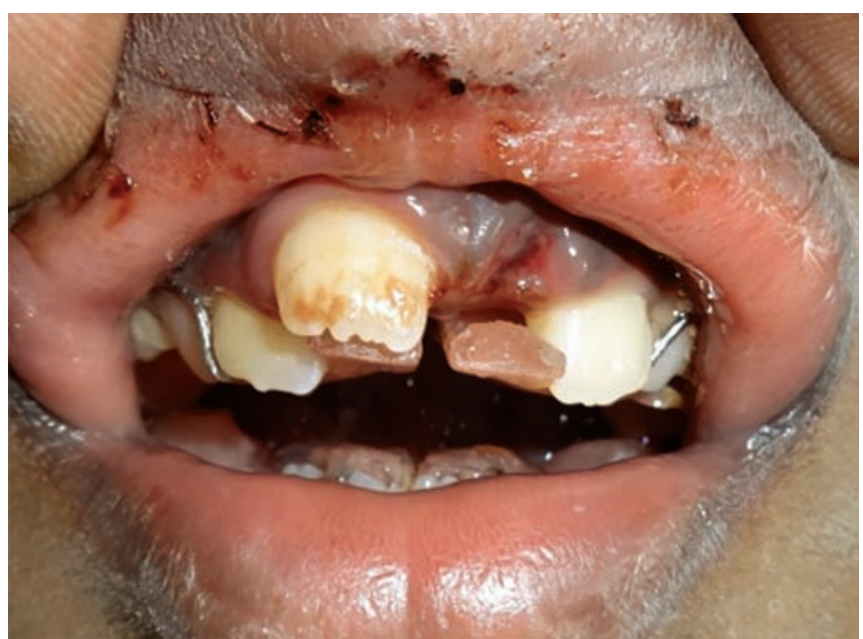

Fig. 4: Avulsed maxillary left central incisor of appliance delivery after 4 months. Patient reported to department with history of facial trauma with avulsed maxillary left central incisor (Fig. 4). Horizontal advancement was carried out by adding acrylic to same appliance. Trimming of appliance was started after 3 months of second step advancement. Trimming was done in occlusogingivally direction at an interval of 3 weeks.

Sagittal correction of class I molar relationship was achieved after 6 months of second step advancement.

After this, phase II was started with fixed appliance (Figs 5A to E) therapy for correction of lower anterior crowding.

\section{DISCUSSION}

Excessive adenoidal growth can have severely damaging effects like abnormal facial growth together with abnormal breathing patterns, congestion, mouth breathing, sleep apnea, rhinosinusitis, swallowing problem, reduced ability to taste, smell, and problems with speech. Thus, it is important for the orthodontist to know the growth pattern of the posterior, and mouth breathing habit is the second most prevalent habit in the age group of 11 to 13 years according to the study conducted by Bhayya and Shyagali ${ }^{6}$ with the incidence rate of $17 \%$.

Myofunctional appliances are the choice of treatment where class II skeletal pattern is due to retrognathic mandible. These appliances reposition the tongue and mandible to a new position leading to changes in airway dimensions. Several studies ${ }^{7,8}$ have reported that modifications of myofunctional appliances are effective in treatment of OSA by improving the airway.

Clark's twin block is a functional appliance based on the concept of occlusal inclined plane. The appliance
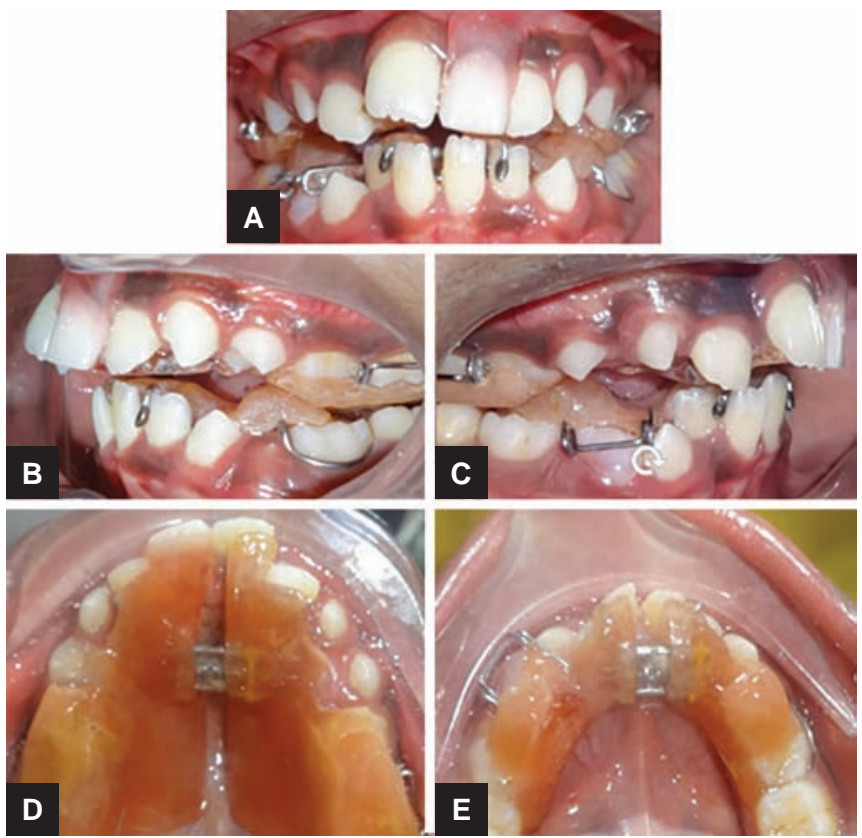

Figs $5 \mathrm{~A}$ to $\mathrm{E}:$ Modified twin block with pontic 
brings the mandible in a forward position and retains it in this position till the desired result is obtained. ${ }^{9,10}$ It allows masticatory function. Patient can wear appliance full time with little discomfort. Other advantages include esthetic, easy to repair, and robust. It is suitable for mixed dentition as well as deciduous dentition. ${ }^{11}$ There were several studies where they have documented the ability of twin block to produce significant skeletal as well as dentoalveolar changes, which in combination correct class II malocclusion. 12,13

In this case, reduction in the pharyngeal space was observed because of the enlarged adenoids in the pretreatment phase. However, after surgical removal of enlarged adenoids and mandibular advancement with the help of twin block therapy, considerable amount of improvement was appreciated as the pharyngeal space significantly increased from 3 to $15 \mathrm{~mm}$. The significant improvement was noted in profile as the Sella Nasion Point A (SNA) remained unchanged and Point A Nasion Point $\mathrm{B}(\mathrm{ANB})$ reduced up to $4^{\circ}$ (Figs $6 \mathrm{~A}$ and $\mathrm{B}$ ), achieving competency of the lips (Fig. 7).

\section{CONCLUSION}

Surgical removal of adenoids along with the use of twin blocks for correction of skeletal class II dysplasia not only
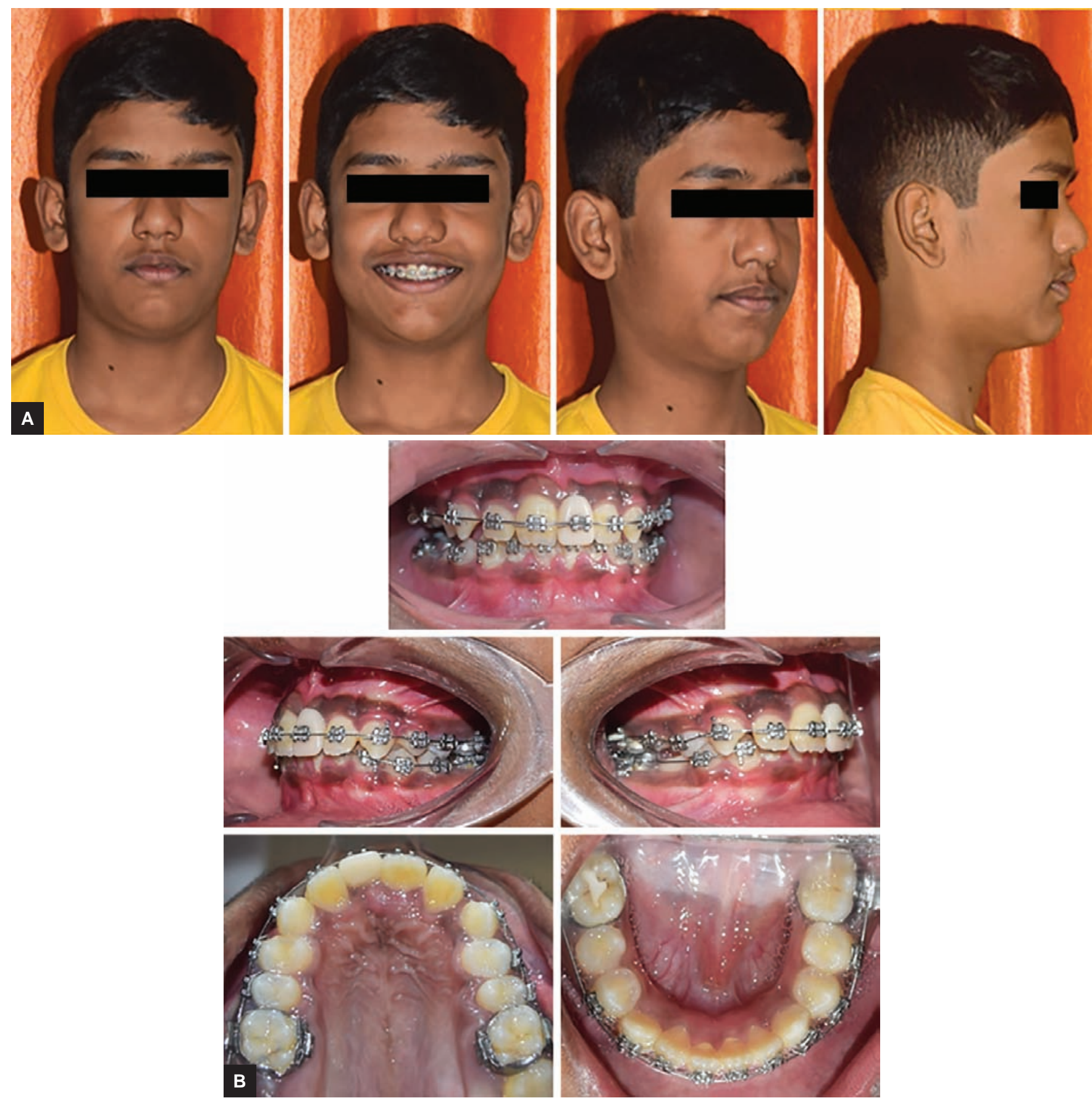

Figs 6A and B: Patient with fixed appliance 

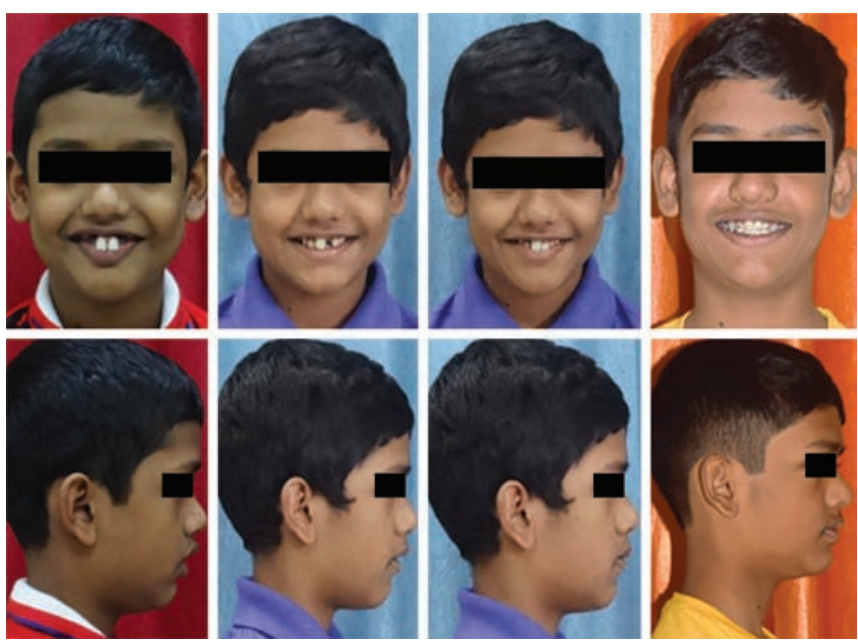

Fig. 7: Treatment progress

improved the profile of the patient but also improved the pharyngeal space, thus eliminating OSA. Hence, dentofacial orthopedics can be used as one of the treatment modality for OSA.

\section{REFERENCES}

1. Valera FC, Travitzk LV, Mattar SE, Matsumoto MA, Elias AM, Anselmo-Lima WT. Muscular, functional and orthodontic changes in pre-school children with enlarged adenoids and tonsils. Int J Pediatr Otorhinolaryngal 2003 Jul;67(7): 761-770.

2. O'Brien K, Wright J, Conboy F, Chadwick S, Connolly I, Cook P, Birnie D, Hammond M, Harradine N, Lewis D, et al. The effectiveness of treatment of Class II malocclusion with the twin block appliance: a randomised, controlled trial. Part 2: psychological effects. Am J Orthod Dentofac Orthop 2003 Nov;124(5):488-495.
3. Chadwick SM, Banks P, Wright JL. The use of myofunctional appliances in the UK: a survey of British orthodontists. Dent Update 1998 Sep;25(7):302-308.

4. Petrovic AG, Stutzmann JJ, Gasson N. The final length of the mandible: is it genetically determined? In: Carlson DS, editor. Craniofacial biology. Monograph No. 10. Ann Arbor (MI): Center for Human Growth and Development, University of Michigan; 1981. p. 105-126.

5. Singh G. Oral habits and their management. In: Textbook of orthodontics. 2nd ed. Jaypee Brothers Medical Publishers Pvt Ltd. p. 581-612.

6. Bhayya DP, Shyagali TR. Prevalence of oral habit in 11-13 year-old school children in Gulbarga city, India. Virtual J Orthod 2009;8(3):1-4.

7. Bonham PE, Currier GF, Orr WC, Othman J, Nanda RS. The effect of a modified functional appliance on obstructive sleep apnea. Am J Orthod Dentofacial Orthop 1988 Nov;94(5): 384-392.

8. Fransson AM, Tegelberg A, Svenson BA, Lennartsson B, Isacsson $\mathrm{G}$. Influence of mandibular protruding device on airway passage and dentofacial characteristics in obstructive sleep apnea and snoring. Am J Orthod Dentofacial Orthop 2002 Oct;122(4):371-379.

9. Clark WJ. The twin block traction technique. Eur J Orthod 1982 May;4(2):129-138.

10. Clark WJ. The twin block technique. A functional orthopaedic appliance system. Am J Orthod Dentofacial Orthop 1988 Jan;93(1):1-18.

11. Al-Anezi SA. Class II malocclusion treatment using combined twin block and fixed orthodontic appliances - a case report. Saudi Dent J 2011 Jan;23(1):43-51.

12. Trenouth MJ. A comparison of twin block, Andresen and removable appliances in the treatment of Class II Division 1 malocclusion. Funct Orthod 1992 Jul-Aug;9(4):26-31.

13. Trenouth MJ. Cephalometric evaluation of the twin-block appliance in the treatment of Class II Division 1 malocclusion with matched normative growth data. Am J Orthod Dentofacial Orthop 2000 Jan;117(1):54-59. 